American Journal of Animal and Veterinary Sciences 7 (1): 42-47, 2012

ISSN 1557-4555

(C) 2012 Science Publications

\title{
Mirtazapine in Veterinary Medicine a Pharmacological Rationale for its Application in Chronic Pain
}

\author{
${ }^{1}$ Mario Giorgi and ${ }^{2}$ Helen Owen \\ ${ }^{1}$ Department of Veterinary Clinics, \\ Faculty of Veterinary Medicine, University of Pisa, \\ Via Livornese (lato monte) 1, San Piero a Grado 56010 Pisa, Italy \\ ${ }^{2}$ School of Veterinary Science, \\ The University of Queensland, Gatton Campus, Gatton, Queensland, 4343, Australia
}

\begin{abstract}
Problem statement: Many recent studies have shown that antidepressant agents have analgesic effects in addition to their intended primary actions. The Tricyclic Antidepressants (TCAs) have been recognized as an effective first-line treatment of human neuropathic pain but unfortunately they display a wide range of side effects. Recent studies have shown that Selective Serotonin Reuptake Inhibitors (SSRI) also have potential analgesic effects, albeit of a lower potency compared with the TCAs. Despite this, there is a trend for their increased use, in place of TCAs, in the treatment of chronic pain. Mirtazapine, a SSRI has been recently investigated in the context of veterinary medicine. It has shown favourable pharmacokinetic profiles. Despite the fact that it has mainly been used for anorexia and as an antiemetic for veterinary patients thus far, it could be potentially useful for the treatment of a wide range of anxiety-related conditions and as an analgesic in chronic and cancerassociated pain, due to its effects on both the noradrenergic and serotonic system. Rationale for the use of mirtazapine in veterinary medicine is reviewed in light of previously published literature. Conclusion/Recommendations: Mirtazapine is proposed as a potential analgesic for use in a multidrug analgesic regime in the context of veterinary medicine. Further studies need to be performed before it is implemented in clinical practice however.
\end{abstract}

Key words: Mirtazapine, SSRI, pain, serotonin, animals

\section{INTRODUCTION}

Many recent studies have shown that antidepressant agents have analgesic effects in addition to their intended primary actions (Lynch, 2001; Sindrup and Jensen, 1999; Davies, 1997; Spiegel et al., 1983). The same studies have also demonstrated that some antidepressants may have analgesic effects. These have been found to be totally independent of their antidepressive effects and to occur at lower doses than are required for anti-depressant actions (Milligan, 1997; Bowsher, 1991; Sindrup et al., 2005; San and Arranz, 2006).

The potential analgesic effects of antidepressants, particularly first-generation antidepressants such as Tricyclic Antidepressants (TCAs), have been demonstrated in many trials. Based on this research, they have been suggested for symptomatic treatment of several conditions such as neuropathic pain (Kalso et al., 1996; Weber, 2001; Sindrup et al., 2005), fibromyalgia (Krell et al., 2005; Arnold et al., 2000), headaches and for migraine prophylaxis (Tomkins et al., 2001). Such is their effectiveness; the TCAs have been recognized as desirable first-line treatment for human neuropathic pain.

Unfortunately, TCAs display a wide scale of side effects. These include drowsiness, dry mouth, blurred vision, constipation, urinary retention, vertigo, impaired sexual function, increase in heart rate, confusion or disorientation, migraine, low blood pressure, light sensitivity, increased appetite, weight gain, nausea and weakness (McCleane, 2008). Discontinuation may result in withdrawal-like side effects such as headache, nausea, vertigo, tiredness and flu-like symptoms (McCleane, 2008). TCAs have the ability to induce extrapyramidal symptoms such as acute or tardive dyskinesia, akathisia, myoclonus, rabbit syndrome and dystonia (Vandel et al., 1997). The symptoms are dose, rather than age related so they can occur in anyone. They are purposeless, repetitive, involuntary and painful movements such as jerking, blinking, tongue movements and muscle spasms.

Corresponding Author: Mario Giorgi, Department of Veterinary Clinics, Faculty of Veterinary Medicine, University of Pisa, Via Livornese (lato monte) 1, San Piero a Grado 56010 Pisa, Italy Tel: +39 502210154 Fax: +39 502210182 


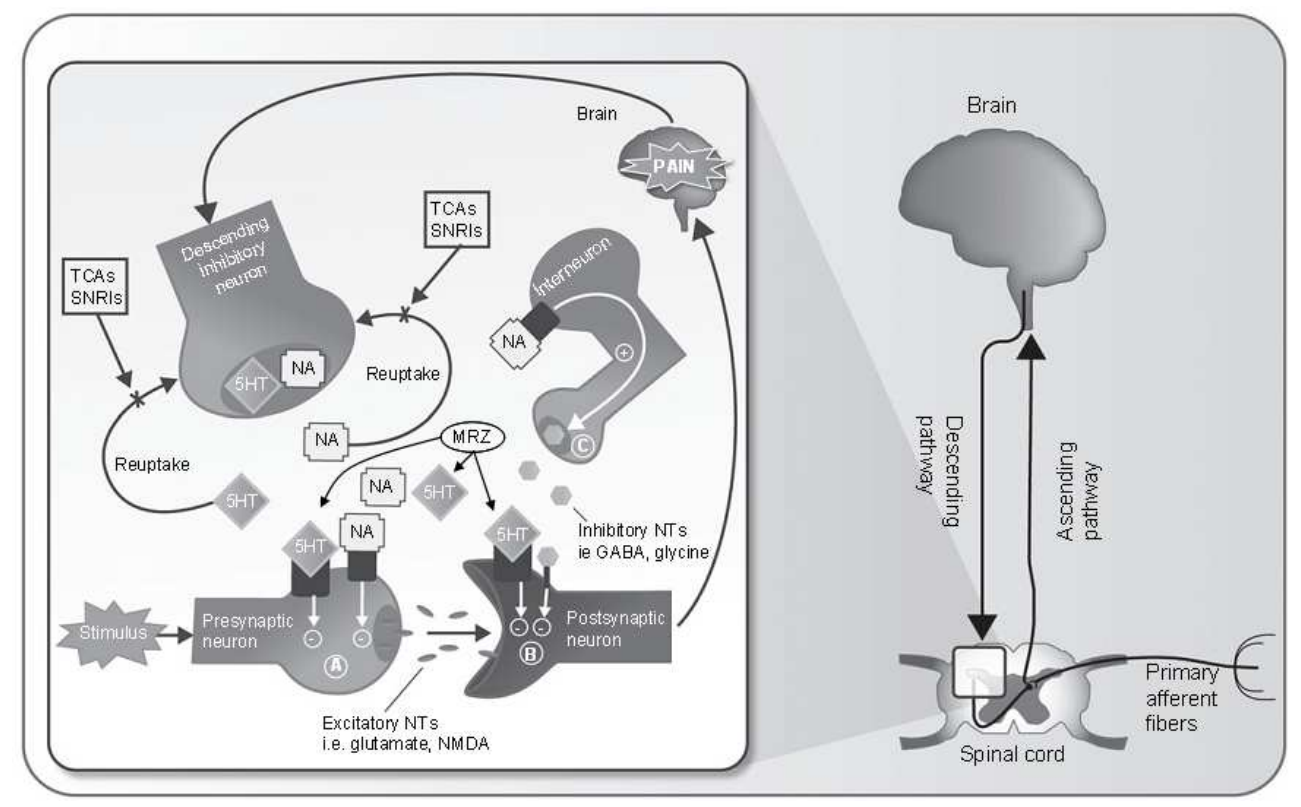

Fig. 1: Monoamine re-uptake inhibitors such as Tricyclic Antidepressants (TCAs) and Serotonin and Norepinephrine Re-uptake Inhibitors (SNRIs) are believed to promote analgesia by increasing the synaptic concentration of Norepinephrine (NE) and/or serotonin (5-HT) within the dorsal horn, thereby (A) inhibiting the release of excitatory neurotransmitter by pre-synaptic neurons; (B) reducing the excitation of postsynaptic neurons and (C) promoting the release of other inhibitory neurotransmitters by interneurons. MRT does not inhibit the reuptake of serotonin or noradrenaline, (Pinder, 1997a). Its activation of 5-HT $1 \mathrm{~A}$ receptors inhibits the excitability of spinothalamic projecting neurons and excitatory interneurons, as well as promotes the $5-\mathrm{HT}_{1 \mathrm{~B} / \mathrm{D}}$ receptor activation through inhibition of neurotransmitter release from primary nociceptive afferents (triggering an antinociceptive effect). The blockade of the 5- $\mathrm{HT}_{2}$ and $5-\mathrm{HT}_{3}$ receptors reduces the likelihood of some serotonergic adverse effects associated with the nonselective serotonin receptor activation of other SSRIs

These symptoms may reoccur even with an appropriate withdrawal regime from TCAs and will not subside without medical treatment (Vandel et al., 1997).

TCAs can also interact with many different drugs that may be being used concurrently resulting in a considerable number of potential side effects. Interactions occur with a wide variety of drugs including alcohol, antihistamines, antihypertensive medications, antipsychotics, aspirin, bicarbonate of soda, diuretics, oral contraceptives, certain blood coagulants, sleeping medications, thyroid medications, tobacco and even some vitamins (Gillman, 2007).

Serotonin and Norepinephrine Re-uptake Inhibitors (SNRIs; e.g., duloxetine and milnacipran) have also been shown to be effective suppressors of pain (Dworkin et al., 2007; Attal et al., 2010). These agents are believed to exert their analgesic effects primarily by increasing the activity of descending pain-suppressing pathways (Fig. 1).

Several studies have shown that Selective Serotonin Reuptake Inhibitors (SSRIs) also have potential analgesic effects, but this effect is lower than that of the TCAs (Giannopoulos et al., 2007; Varia et $a l ., 2000)$. Because they are associated with fewer side effects however, they have recently started to replace TCAs in the treatment of chronic pain (Miller and Rabe-Jablonska, 2005).

Mirtazapine (MRZ), belongs to the SSRI class. The antidepressant activity of this drug is thought to result from a combination of noradrenergic and serotonergic effects (Boer et al., 1995). MRZ enhances noradrenergic and 5- $\mathrm{HT}_{1 \mathrm{~A}}$-mediated serotonergic neurotransmission via antagonism of central $\alpha_{2}-$ adrenergic autoreceptors and heteroreceptors and through the postsynaptic blockade of 5- $\mathrm{HT}_{2}$ and $5-\mathrm{HT}_{3}$ receptors (Boer et al., 1995).

MRZ does not inhibit the reuptake of serotonin or noradrenaline, nor does it inhibit monoamine oxidase activity, these properties differentiate it from several other classes of antidepressant drugs (Pinder, 1997a). In theory, blockade of the $5-\mathrm{HT}_{2}$ and $5-\mathrm{HT}_{3}$ receptors by MRZ could reduce the likelihood of some serotonergic 
adverse effects associated with the nonselective serotonin receptor activation of SSRIs and venlafaxine (e.g., restlessness, nausea and sexual dysfunction) (Pinder, 1997a; 1997b) and this appears to be supported by tolerability data from clinical trials. The mechanism of action of MRZ therefore also incidentally causes pain reduction because the descending serotonergic pathways can inhibit nociceptive signaling via $5-\mathrm{HT}_{1}$ receptor activation (Fig. 1). Specifically, activation of $5-\mathrm{HT}_{1 \mathrm{~A}}$ receptors inhibits the excitability of spinothalamic projecting neurons and excitatory (i.e., pain facilitatory) interneurons (Benarroch, 2008). Similarly, $5-\mathrm{HT}_{1 \mathrm{~B} / \mathrm{D}}$ receptor activation is antinociceptive through inhibition of neurotransmitter release from primary nociceptive afferents (Benarroch, 2008). In contrast, descending serotonergic pathway activation can promote nociceptive transmission by activating $5-\mathrm{HT}_{2 / 3}$ neurons (Benarroch, 2008; Zeitz et al., 2002).

In addition to its antidepressant effect, MRZ has a number of other pharmacodynamic effects. For example, blockade of $5-\mathrm{HT}_{2}$ receptors is associated with improvement in sleep quality (Pinder, 1997a), indeed, MRZ improves the quality and duration of sleep and unlike SSRIs, does not suppress rapid eye movement sleep (Aslan et al., 2002; Winokur et al., 2003; Shen et al., 2006). Although the initial dose of MRZ can cause psychomotor impairment (affecting driving ability), this is not sustained during continuing treatment (Ridout et al., 2003; Wingen et al., 2005). Interestingly, unlike reuptake inhibitors which can increase cortisol levels, (Schule et al., 2003) MRZ suppresses the secretion of cortisol.

The biotransformation of MRZ occurs primarily via the cytochrome P450 enzyme system in humans. MRZ is predominantly metabolized to $8-\mathrm{OH}$ mirtazapine (8-OH) and to Desmethylmirtazapine (DMR) (Fig. 2). The former metabolite has no pharmacological effect, while DMR has been estimated to contribute $5-10 \%$ of the total pharmacodynamic activity of the drug (Delbressine et al., 1998).

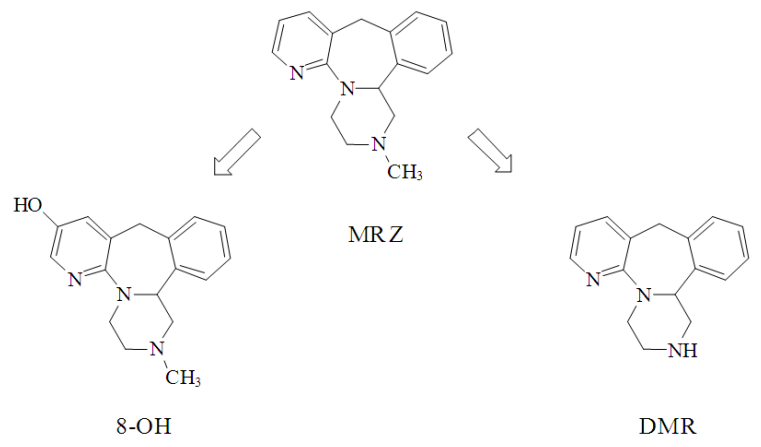

Fig. 2: Molecular structure of MRZ and its metabolites DMR and 8-OH
Recently, MRZ has been tested in cats (Quimby et al., 2011), dogs (Giorgi and Yun, 2011) and horses (Rouini et al., 2012). MRZ orally administered in the dose range (1.88-3.75 mg/cat day) caused significant polyphagia in cats, this pharmacokinetic behaviour is different to that of human beings. In canine species, MRZ orally administered (at about $1 \mathrm{mg} \mathrm{kg}^{-1}$ ) showed a favourable pharmacokinetic profile (which is different to that in both cats and humans) compared to other CNS active drugs such as clomipramine (King et al., 2000), fluoxetine (Simpson et al., 2007) and trazodone (Gruen and Sherman, 2008). For these reasons, it was speculated (Giorgi, 2012) to be potentially useful for veterinary patients for treatment of anorexia and a wide range of anxiety-related conditions (Overall, 2000), for its antiemetic properties (due to antagonism of $5-\mathrm{HT}_{3}$ receptor) and as an analgesic in chronic and cancerassociated pain, due to its effects on both the noradrenergic and serotonic system (Bannister et al., 2009). Pharmacokinetics and metabolism have been reported to be largely variable among these species. Although MRZ has shown a good safety profile (better than other antidepressive drugs (Giorgi and Yun, 2011), caution should be taken in extrapolating doses from other species or humans.

It is likely to have additional applications for veterinary use, in particular, it has been suggested that its noradrenergic and serotonic system effects could be exploited for analgesic use (Bomholt et al., 2005). In this application, MRZ could represent a therapeutic option that results in a Non Steroidal AntiInflammatory (NSAIDs)-sparing effect, i.e., utilizing the noradrenergic and specific serotonergic analgesic effects to lower the required dose of NSAIDs. This combined use would reduce the likelihood and intensity of NSAIDs-induced side effects. This prospective application is highly attractive, especially in dogs and horses, species extremely susceptible to the adverse effects of NSAIDs.

A recent study effectively explained MRZ's effectiveness on pain in rodents (Kilic et al., 2011). It was demonstrated that MRZ had significant antinociceptive activity at the supraspinal level (hot plate test) and that antinociceptive activity was reduced when the dose was increased, explicitly, it has a biphasic activity. It is well established that serotonin has analgesic activity at the central level and analgesic activity at the peripheral level (Clauw and McCarberg, 2012). It was also demonstrated that MRZ has significant antinociceptive activity at the peripheral level (writhing test) and that the analgesic activity was reduced when the dose is increased. It is likely that this is associated with the emergence of peripheral analgesic 
activity of serotonin when the dose is increased. It has been demonstrated that opioidergic mechanisms are also involved at these two levels (supra spinal and peripheral) (Giorgi, 2012). In contrast, MRZ had no antinociceptive activity at the central spinal level (tail clip and flick tests). Additionally, it has been demonstrated through the use of nitric oxide synthase inhibitors, that the NO and nitrergic pathways are not involved in the central analgesic activity of MRZ.

Interestingly, the antinociceptive effect of MRZ has been detected as soon as 30 minutes following drug administration. This supports the theory that the analgesic effect is independent of the antidepressive effect which takes 2 weeks for on-set. Despite this, there are some concerning data related to the oral bioavailability of this drug. This has been reported in approximately $3 \%$ of rats (Rouini and Giorgi, personal communication). As MRZ is predominantly administered orally and its bioavailability might vary widely among animal species, this data should be carefully evaluated in each species.

Given the complexity of pain and the variety of physiological mechanisms involved, single-agent regimens may not provide optimal analgesia for certain types of pain because they influence a limited number of therapeutic targets in the pain transmission and modulatory pathways (Raffa, 2006). Multidrug analgesic approaches take advantage of the complementary mechanisms of different drug classes to enhance analgesia and/or reduce side effects by lowering the required dose of one or more agents. The practice of combining MRZ with other analgesic agents is common and has been integrated into human clinical practice guidelines for the treatment of both acute and chronic pain (NIH, 1997; 2010; Dworkin et al., 2007). Based on the information described in this study, MRZ is offered as a potential analgesic in veterinary species in a multidrug analgesic approach rather than as a single active ingredient. Further studies need to be carried out before its employment in clinical practice however.

\section{REFERENCES}

Arnold, L.M., P.E. Keck Jr. and J.A. Welge, 2000. Antidepressant treatment of fibromyalgia. A metaanalysis and review. Psychosomatics, 41: 104-113. PMID: 10749947

Aslan, S., E. Isik and B. Cosar, 2002. The effects of mirtazapine on sleep: A placebo controlled, double-blind study in young healthy volunteers. Sleep, 25: 677-679. PMID: 12224847
Attal, N., G. Cruccu, R. Baron, M. Haanpaa and P. Hansson et al., 2010. EFNS guidelines on the pharmacological treatment of neuropathic pain: 2010 revision. Eur. J. Neurol., 17: 1113-1188. PMID: 20402746

Bannister, K., L.A. Bee and A.H. Dickenson, 2009. Preclinical and early clinical investigations related to monoaminergic pain modulation. Neurotherapeutics, 6: 703-712. PMID: 19789074

Benarroch, E.E., 2008. Descending monoaminergic pain modulation: bidirectional control and clinical relevance. Neurology, 71: 217-221. PMID: 18625968

Boer, T.D., G.S.F. Ruigt and H.H.G. Berendsen, 1995. The $\alpha 2$-selective adrenoceptor antagonist org 3770 (mirtazapine, Remeron $®)$ enhances noradrenergic and serotonergic transmission. Hum. Psychopharmacol. Clin. Exp., 10: S107-S118. DOI: 10.1002/hup.470100805

Bomholt, S.F., J.D. Mikkelsen and G. BlackburnMunro, 2005. Antinociceptive effects of the antidepressants amitriptyline, duloxetine, mirtazapine and citalopram in animal models of acute, persistent and neuropathic pain. Neuropharmacology, 48: 252-263. PMID: 15695164

Bowsher, D., 1991. Neurogenic pain syndromes and their management. Br. Med. Bull., 47: 644-666. PMID: 1794077

Clauw, D. and B.H. McCarberg, 2012. Managing chronic pain with nonopioid analgesics: A multidisciplinary consult. Am. J. Med., 125: S1-S1. PMID: 22482859

Davies, J., 1997. A strategy for chronic pain. Practitioner, 241: 452-458, PMID: 9425705

Delbressine, L.P., M.E. Moonen, F.M. Kaspersen, G.N. Wagenaars and P.L. Jacobs et al., 1998. Pharmacokinetics and biotransformation of mirtazapine in human volunteers. Clin. Drug Invest., 15: 45-55. PMID: 18370465

Dworkin, R.H., A.B. O'Connor, M. Backonja, J.T. Farrar and N.B. Finnerup et al., 2007. Pharmacologic management of neuropathic pain: Evidence-based recommendations. Pain, 132: 237251. PMID: 17920770

Giannopoulos, S., M. Kosmidou, I. Sarmas, S. Markoula and S.H. Pelidou et al., 2007. Patient compliance with SSRIs and gabapentin in painful diabetic neuropathy. Clin. J. Pain, 23: 267-269. PMID: 17314587

Gillman, P.K., 2007. Tricyclic antidepressant pharmacology and therapeutic drug interactions updated. Br. J. Pharmacol., 151: 737-748. PMID: 17471183 
Giorgi, M. and H. Yun, 2011. Pharmacokinetics of mirtazapine and its main metabolites in Beagle dogs: A pilot study. Vet. J., 192: 239-241. PMID: 21652240

Giorgi, M., 2012. Tramadol vs tapentadol: A new horizon in pain treatment? Am. J. Anim. Vet. Sci., 7: 7-11. DOI: 10.3844/ajavsp.2012.7.11

Gruen, M.E. and B.L. Sherman, 2008. Use of trazodone as an adjunctive agent in the treatment of canine anxiety disorders: 56 cases (1995-2007). J. Am. Vet. Med. Assoc., 233: 1902-1907. PMID: 19072606

Kalso, E., T. Tasmuth and P.J. Neuvonen, 1996. Amitriptyline effectively relieves neuropathic pain following treatment of breast cancer. Pain, 64: 293302. PMID: 8740607

Kilic, F.S., A.E. Dogan, C. Baydemir and K. Erol, 2011. The acute effects of mirtazapine on pain related behavior in healthy animals. Neurosciences, 16: 217-223. PMID: 21677610

King, J.N., B.S. Simpson, K.L. Overall, D. Appleby and P. Pageat et al., 2000. Treatment of separation anxiety in dogs with clomipramine: Results from a prospective, randomized, double-blind, placebocontrolled, parallel-group, multicenter clinical trial. Applied Anim. Behav. Sci., 67: 255-275. PMID: 10760607

Krell, H.V., A.F. Leuchter, I.A. Cook and M. Abrams, 2005. Evaluation of reboxetine, a noradrenergic antidepressant, for the treatment of fibromyalgia and chronic low back pain. Psychosomatics, 46: 379-384. PMID: 16145181

Lynch, M.E., 2001. Antidepressants as analgesics: A review of randomized controlled trials. J. Psychiatry Neurosci., 26: 30-36. PMID: 11212591

McCleane, G., 2008. Antidepressants as analgesics. CNS Drugs, 22: 139-156. PMID: 18193925

Miller, A. and J. Rabe-Jablonska, 2005. The effectiveness of antidepressants in the treatment of chronic non-cancer pain--a review. Psychiatr. Pol., 39: 21-32. PMID: 15771151

Milligan, K., 1997. Prescribing antidepressants in general practice. Tricyclic antidepressants are also used for relief of chronic pain. Br. Med. J., 314: 827-828. PMID: 9081015

NIH, 1997. Practice guidelines for chronic pain management. A report by the American Society of Anesthesiologists Task Force on Pain Management, Chronic Pain Section. Anesthesiology, 86: 995-1004. PMID: 9105246
NIH, 2010. Practice guidelines for chronic pain management: an updated report by the American Society of Anesthesiologists Task Force on Chronic Pain Management and the American Society of Regional Anesthesia and Pain Medicine. Anesthesiology, 112: 810-833. PMID: 20124882

Overall, K.L., 2000. Natural animal models of human psychiatric conditions: Assessment of mechanism and validity. Prog. Neuropsychopharmacol. Biol. Psych., 24: 727-776. PMID: 11191711

Pinder, R.M., 1997a. Designing a new generation of antidepressant drugs. Acta Psychiatr. Scand., 96: S7-13. DOI: 10.1111/j.1600-0447.1997.tb05953.x

Pinder, R.M., 1997b. The pharmacologic rationale for the clinical use of antidepressants. J. Clin. Psychiatr., 58: 501-508. PMID: 9413422

Quimby, J.M., D.L. Gustafson, B.J. Samber and K.F. Lunn, 2011. Studies on the pharmacokinetics and pharmacodynamics of mirtazapine in healthy young cats. J. Vet. Pharmacol. Ther., 34: 388-396. DOI: $10.1111 / \mathrm{j} .1365-2885.2010 .01244 . x$

Raffa, R., 2006. Pharmacological aspects of successful long-term analgesia. Clin. Rheumatol., 25: 9-15. DOI: $10.1007 / \mathrm{s} 10067-006-0201-\mathrm{x}$

Ridout, F., R. Meadows, S. Johnsen and I. Hindmarch, 2003. A placebo controlled investigation into the effects of paroxetine and mirtazapine on measures related to car driving performance. Hum. Psychopharmacol., 18: 261-269. PMID: 12766930

Rouini, M.R., H. Lavasani, B. Sheikholeslami, V. Nikoui and A. Bakhtiarian et al., 2012. Pharmacokinetics of mirtazapine and its main metabolites after single oral administration in fasting/fed horses. J. Equine Vet. Sci.

San, L. and B. Arranz, 2006. Mirtazapine: Only for depression? Acta Neuropsychiatr., 18: 130-143. DOI: $10.1111 / \mathrm{j} .1601-5215.2006 .00143 . x$

Schule, C., T. Baghai, C. Rackwitz and G. Laakmann, 2003. Influence of mirtazapine on urinary free cortisol excretion in depressed patients. Psychiatry Res., 120: 257-264. PMID: 14561437

Shen, J., S.A. Chung, L. Kayumov, H. Moller and N. Hossain et al., 2006. Polysomnographic and symptomatological analyses of major depressive disorder patients treated with mirtazapine. Can. J. Psychiatry, 51: 27-34. PMID: 16491981

Simpson, B.S., G.M. Landsberg, I.R. Reisner, J.J. Ciribassi and D. Horwitz et al., 2007. Effects of reconcile (fluoxetine) chewable tablets plus behavior management for canine separation anxiety. Vet. Ther., 8: 18-31. PMID: 17447222 
Sindrup, S.H. and T.S. Jensen, 1999. Efficacy of pharmacological treatments of neuropathic pain: An update and effect related to mechanism of drug action. Pain, 83: 389-400. PMID: 10568846

Sindrup, S.H., M. Otto, N.B. Finnerup and T.S. Jensen, 2005. Antidepressants in the treatment of neuropathic pain. Basic Clin. Pharmacol. Toxicol., 96: 399-409. PMID: 15910402

Spiegel, K., R. Kalb and G.W. Pasternak, 1983. Analgesic activity of tricyclic antidepressants. Ann. Neurol., $\quad 13$ : $\quad 462-465 . \quad$ DOI: 10.1002/ana.410130418

Tomkins, G.E., J.L. Jackson, P.G. O’Malley, E. Balden and J.E. Santoro, 2001. Treatment of chronic headache with antidepressants: A meta-analysis. Am. J. Med., 111: 54-63. DOI: 10.1016/S00029343(01)00762-8

Vandel, P., B. Bonin, E. Leveque, D. Sechter and P. Bizouard, 1997. Tricyclic antidepressant-induced extrapyramidal side effects. Eur. Neuropsychopharmacol., 7: 207-212. PMID: 9213080

Varia, I., E. Logue, C. O'connor, K. Newby and H.R. Wagner et al., 2000. Randomized trial of sertraline in patients with unexplained chest pain of noncardiac origin. Am. Heart J., 140: 367-372. PMID: 10966532
Weber, W.E., 2001. Pharmacotherapy for neuropathic pain caused by injury to the afferent nerve fibers. Ned. Tijdschr. Geneeskd., 145: 813-617. PMID: 11370425

Wingen, M., J. Bothmer, S. Langer and J.G. Ramaekers, 2005. Actual driving performance and psychomotor function in healthy subjects after acute and subchronic treatment with escitalopram, mirtazapine and placebo: A crossover trial. J. Clin. Psychiatry, 66: 436-443. PMID: 15816785

Winokur, A., N.A. DeMartinis, D.P. McNally, E.M. Gary and J.L. Cormier et al., 2003. Comparative effects of mirtazapine and fluoxetine on sleep physiology measures in patients with major depression and insomnia. J. Clin. Psychiatry, 64: 1224-1229. PMID: 14658972

Zeitz, K.P., N. Guy, A.B. Malmberg, W.J. Martin and L. Sun et al., 2002. The 5-HT3 subtype of serotonin receptor contributes to nociceptive processing via a novel subset of myelinated and unmyelinated nociceptors. J. Neurosci., 22: 10101019. PMID: 11826129 